\title{
Haplotype analysis of the IGF2-INS-TH gene cluster in Parkinson's disease
}

Greg Sutherland ${ }^{1}$, George Mellick ${ }^{1}$, Jeremy Newman ${ }^{1}$, Kay L Double ${ }^{2}$, Julia Stevens ${ }^{2}$, Linda Lee $^{2}$, Dominic Rowe ${ }^{3}$, Peter Silburn ${ }^{1}$, Glenda M Halliday ${ }^{2}$

1. Eskitis Institute, School of Biomolecular and Biomedical Sciences, Griffith University, Brisbane, Australia.

2. Prince of Wales Medical Research Institute and the University of New South Wales, Sydney, Australia.

3. Department of Neurology, Royal North Shore Hospital and the University of Sydney, Sydney, Australia.

Corresponding author: Professor Glenda Halliday, Prince of Wales Medical Research Institute, Barker Street, Randwick NSW, 2031 Australia, phone +61-2-9399 1104, fax +61-29399 1105, email G.Halliday@unsw.edu.au

Short title: IGF2-INS-TH haplotypes in Parkinson's disease

Abstract: 184 words Text word count: 2422

Number of: text pages: 8 figures: 1 tables: 3 Supplementary tables: 1 


\begin{abstract}
Idiopathic Parkinson's disease is a common movement disorder characterised by a loss of dopaminergic neurons in the substantia nigra. Its pathogenesis is postulated to involve complex interactions between genetic susceptibility and environmental exposures. The IGF2INS-TH gene cluster on the telomeric end of human chromosome 11 is a gene rich region expressing several proteins important for dopamine neuron homeostasis. We used a haplotyping approach to determine whether common genetic variation in the IGF2-INS-TH cluster influences the risk of idiopathic Parkinson's disease in a Caucasian case-control group recruited from Brisbane, Australia. Three tagging polymorphisms, the SNPs, rs680 and rs689 and the microsatellite, HUMTH01, were genotyped in 215 cases and 215 age- and gendermatched controls. Eight common haplotypes accounted for $91 \%$ of the genetic variation in our control group and one haplotype, IGF2-INS-TH*6, was significantly under-represented among the cases with idiopathic Parkinson's disease (OR $=0.42$, 95\% C.I. $=0.25-0.72$, pvalue $=0.001)$. Analysis of the individual polymorphisms showed that the IGF2-rs680 alternate ' $A$ ' allele accounted for the majority of the protective effect. Our findings suggest that common genetic variants in the IGF2-INS-TH cluster modify susceptibility to idiopathic Parkinson's disease.
\end{abstract}

Key words: association, chromosome 11, insulin-like growth factor 2, Parkinson’s disease, tyrosine hydroxylase 


\section{INTRODUCTION}

Idiopathic Parkinson's disease (PD) is characterised by the selective loss of dopamine neurons in the substantia nigra and is responsive to the exogenous administration of levodopa (L-DOPA)(Litvan et al. 2007). The neurons that degenerate contain the rate-limiting enzyme for dopamine synthesis, tyrosine hydroxylase (TH). Growth factors, including insulin-like growth factors (IGF) can protect against environmental toxins used to produce animal models of PD (Quesada and Micevych 2004; Chung et al. 2005). While the cause/s of PD remain unknown, there is evidence that complex interactions between genetic susceptibility and environmental exposures are involved (Le Couteur et al. 2002). In particular, the genetic component of PD is postulated to be a combination of small incremental risks from common variants of multiple genes. Linkage disequilibrium-based mapping approaches, such as haplotype analysis, allow this common disease - common variant hypothesis to be investigated using a minimal amount of markers per loci (Doris 2002).

The telomeric end of the short arm of chromosome $11(11 \mathrm{p} 15.5)$ is a gene-rich region containing the IGF2, proinsulin precursor (INS) and TH genes (Figure 1); all of which are important for dopamine neuron homeostasis. A previous haplotype analysis of the IGF2-INSTH region identified three ‘tagging’ polymorphisms (Figure 1): the single nucleotide polymorphisms (SNP), IGF2-rs680 and INS-rs689; and HUMTH01, a tetranucleotide repeat marker in the $T H$ gene (Rodriguez et al. 2004). Associations were subsequently found between particular IGF2-INS-TH haplotypes and cardiovascular risk factors, such as high body fat percentage, plasma triglycerides and blood pressure (Rodriguez et al. 2004) and initiation of regular smoking (Rodriguez et al. 2006). This latter study supported other groups who found associations between the HUMTH01 marker per se and smoking behaviour (Anney et al. 2004; Olsson et al. 2004). Interestingly, these same risk factors occur less 
frequently in PD patients compared with controls (Haugarvoll et al. 2005; Scigliano et al. 2006), suggesting that common variants in the IGF2-INS-TH gene cluster may also affect susceptibility for PD. The TH gene has been previously discounted as a PD susceptibility gene, although only single polymorphic markers were investigated in these studies (PlanteBordeneuve et al. 1994; Kunugi et al. 1998; Mizuta et al. 2006). Furthermore the potential confounding influence of smoking behaviour was not considered in these studies. We therefore investigated the potential role of IGF2, INS and TH genes, along with the known protective factor smoking, in PD susceptibility.

\section{*** Figure 1 about here ${ }^{* * *}$}

\section{MATERIALS AND METHODS}

\section{Case recruitment and phenotyping}

Caucasian PD cases were recruited by an experienced neurologist (PS) at both private and public movement disorders clinics in Brisbane, Australia. Informed consent for participation in the study was obtained following approval by the human research ethics committees at each of the participating institutions, in accordance with the Declaration of Helsinki. Standard criteria for the diagnosis of probable PD was used (Gelb et al. 1999). Patients were excluded if they had no response to levodopa, or they had cognitive decline. A standard questionnaire was completed to obtain detailed epidemiological information including smoking behaviour. Subjects were considered smokers if they had ever smoked at least one cigarette per day for a period of a year or more (Deng et al. 2004). Controls of Caucasian ancestry were a combination of spouses (37\%) and electoral roll volunteers who underwent the same data collection procedures and were excluded if screening responses suggested any possibility of movement or cognitive disorders. Blood was collected for subsequent DNA extraction from 
215 PD cases (mean age $=71 \pm$ S.D. of 9 years, M/F = 129/86) and 215 age and gendermatched controls (mean age $=71 \pm 9$ years, $M / F=129 / 86)$.

\section{Genotyping}

Design and implementation of genotyping assays for SNPs, rs680 and rs689, was carried out by the Australian Genome Research Facility in Brisbane, using the Sequenom Platform. HUMTH01 PCR amplification (Sharma et al. 1998) was performed using the primers: forward 5’(HEX)-TCCAAAAAATCCAAGATGGC-3’ and reverse 5'ACAGGGAACACAGACTCCATG-3’. Briefly 50 ng genomic DNA was incubated with the TH primers (both $0.2 \mu \mathrm{M}$ ) in a solution of $1.5 \mathrm{mM} \mathrm{MgCl}_{2}, 0.1 \mathrm{mM}$ dNTPs, $0.5 \mathrm{U}$ native Taq polymerase in a final volume of $20 \mu \mathrm{l}$ (Invitrogen, Carlsbad, California, USA). Cycling conditions were $94^{\circ} \mathrm{C}$ for 3 minutes, then 35 cycles of $94^{\circ} \mathrm{C}$ for 30 seconds, $56^{\circ} \mathrm{C}$ for 30 seconds and $72^{\circ} \mathrm{C}$ for 35 seconds, followed by $72^{\circ} \mathrm{C}$ for 7 minutes. PCR products were resolved by electrophoresis on a 6\% 7M urea denaturing polyacrylamide gel, using the Gelscan 2000 real-time gel system (Corbett Research, Mortlake, NSW, Australia). Identical results were obtained on duplicates of $10 \%$ of the samples. Genotyping efficiency was $98 \%$ for both the rs680 and rs689 assays and 100\% for HUMTH01; 209 controls (mean age = 71士 S.D. of 9 years, $M / F=126 / 83$, smokers $=53 \%$ ) and 210 PD cases (mean age $=71 \pm$ S.D. of 9 years, mean age at onset $=58 \pm$ S.D. of 10 years, $M / F=125 / 85$, smokers $=47 \%$ ) were included in the final haplotype analysis (see below). IGF2-INS-TH haplotype nomenclature has been previously described (Rodriguez et al. 2004).

\section{Statistics}

A nominal statistical significance level of $<0.05$ was used for all tests unless modified for multiple comparisons using Bonferroni’s correction. Hardy-Weinberg equilibrium analyses 
were performed (web-based $\chi^{2}$ analyses:

http://www.kursus.kvl.dk/shares/vetgen/_Popgen/genetik/applets/kitest.htm) to assess genotyping reliability. Haplotype differences between PD cases and controls were assessed with $\chi^{2}$ analysis using the 'EH' program (version 15; http://www.genemapping.cn/eh.htm). The program utilises an expectation-maximisation algorithm to handle unphased data. Haplotype crude odds ratios (OR) were calculated using a web-based calculator (http://statpages.org/ctab2x2.html). Linkage disequilibrium analysis was calculated using the ‘2LD’ program (http://www.mrc-epid.cam.ac.uk/Personal/jinghua.zhao/software.htm) incorporating 'EH' generated haplotype data. Uncommon haplotypes were combined to reduce cells and all other haplotypes used as the reference. Further explorative statistics to determine any underlying individual allelic or genotypic polymorphisms associated with PD were assessed using $\chi^{2}$ analyses (SPSS Version 13.0). Binomial logistic regression modelling was used to adjust the ORs for age, gender, and smoking status. Variables that were significantly difference in these univariate regression analyses were included in a final multivariate regression model.

\section{RESULTS}

The rs680 and HUMTH01 markers were in Hardy-Weinberg equilibrium for both cases and control populations ( $\mathrm{p}>0.6$ ). The rs689 marker for cases was in Hardy-Weinberg equilibrium ( $p=0.6$ ), but the controls were outside Hardy-Weinberg equilibrium for this marker (0.04). However, there were no ambiguities between replicates for these samples. Eight common IGF2-INS-TH haplotypes accounted for 91\% of all haplotypes among the controls (Table 1). A $\chi^{2}$ analysis of all haplotype frequencies showed a significant difference between PD cases and controls $\left(\chi^{2}=20.4\right.$, degrees of freedom $\left.(\mathrm{df})=8, \mathrm{p} \leq 0.01\right)$. Further analysis of individual 
haplotypes showed that IGF2-INS-TH*6 $\left({ }^{*} 6\right)$ was significantly under-represented in PD (OR $=0.42$ 95\% C.I. $=0.25-0.72, \mathrm{p} \leq 0.001)$ whereas $* 8$ was over-represented $(\mathrm{OR}=2.31(1.17-$ 4.56), $\mathrm{p} \leq 0.02$ ) (Table 1$)$. However, the $* 8$ effect would not survive a strict adjustment for multiple comparisons (level of significance $\leq 0.006$ ). The *6 haplotype consisted of the alternate alleles for both SNPs combined with the longest HUMTH01 allele 'e', whereas *8 had the major IGF2 allele (G) and HUMTH01 ‘c’ allele (Table 1).

\section{*** Table 1 about here ***}

To determine whether the haplotype effects above could be attributed to any particular individual polymorphisms, further exploratory statistics were performed. There were no allele or genotype associations observed for rs689, however both the minor allele 'A' of rs680 (OR = 0.73, 95\% C.I. $=0.54-0.99$, p-value $=0.04)($ Supplementary Table S1 $)$ and 'AA' homozygotes cases $(\mathrm{OR}=0.37,95 \%$ C.I. $=0.17-0.83, \mathrm{p}$-value $=0.02)($ Table 2$)$ were significantly reduced among PD. As previously reported (Sharma et al. 1998), five different HUMTH01 alleles (a, b, c, d and e) relating to 6, 7, 8, 9 and 9.3 TCAT repeats were observed in our group. A $\chi^{2}$ analysis of all HUMTH01 alleles showed no significant differences $\left(\chi^{2}=\right.$ 7.45, $\mathrm{df}=4$, $\mathrm{p}$-value $\geq 0.11$ ) between cases and controls. However genotype analysis showed that ' $\mathrm{e}$ ' allele carriers were under-represented among PD cases (non-corrected $\mathrm{OR}=0.66$, 95\% C.I. $=0.45-0.97, \mathrm{p}$-value $=0.04)($ Table 2 and Supplementary Table S1).

\section{*** Table 2 about here $* * *$}

Finally a logistic multivariate regression analysis including the rs680 'AA' genotype and HUMTH01 'e' carrier genotypes was carried out. This suggested that the majority of the *6 protective effect was associated with rs680 $(\mathrm{OR}=0.72,95 \%$ C.I. $=0.53-0.98$, p-value $=0.03)$ (Table 3). The protective effect seen with HUMTH01 'e' allele carriers was reduced to a strong trend $(\mathrm{OR}=0.68,95 \%$ C.I $=0.46-1.01, \mathrm{p}=0.06)$ (Table 3$)$ suggesting that the e allele also contributes to the outcome, albeit to a lesser extent. 


\section{DISCUSSION}

This is the first case-control analysis of IGF2-INS-TH haplotype in PD, although polymorphic variability in the $\mathrm{TH}$ gene has been previously investigated (Plante-Bordeneuve et al. 1994; Kunugi et al. 1998; Mizuta et al. 2006). Our results indicate that the expression of the common haplotype *6 reduces the risk for PD. Multivariate logistic regression modelling suggested that the rs680 'A' allele probably accounts for the majority of this effect as the significance of the HUMTH01 'e' carrier genotype was lost in this analysis (Table 3). There was modest linkage disequilibrium between the HUMTH01 and rs680 markers ( $D^{\prime}=0.48$; p $=0$ ) so it is possible that both may be proxies for the same functional entity with an influence on disease outcome. However, given that HUMTH01 'e' carrier status, adjusted for the influence of the rs680 genotype, continued to make a modest contribution to the outcome it seems more likely that there are at least two protective entities on the *6 background.

We did not find significant differences in the overall allele frequencies of the HUMTH01 microsatellite, consistent with previous negative case-control reports (Plante-Bordeneuve et al. 1994) (Supplementary Table S1). However HUMTH01 may act as a marker for causative variants rather than being a functional variant per se. In that case, the detection of subtle differences between common haplotypes in our study suggests that analysis of HUMTH01 alone gives an incomplete picture of the common genetic variation in and around the $T H$ gene. While the 'e' allele of HUMTH01 features in the *6 haplotype, it is also seen on the *3 and *4 backgrounds, whose frequencies were similar between cases and controls in our study, thus diluting any independent association effect. This diluting effect could also explain the 
variation seen in previous in vitro and in vivo studies assessing HUMTH01's effect on TH expression. One in vitro study revealed a length-dependent reduction in transcription up to eight repeats (c allele) but no further reduction or enhancement of transcription with larger repeats (Albanese et al. 2001). Their result suggests that the 'a' allele should be associated with the highest TH activity in vivo. However in vivo studies actually suggest that the longer 'e’ allele has the highest enzyme activity (Sharma et al. 1998; Zhang et al. 2004), although this finding also lacks consistency (Wei et al. 1997).

TH gene variability has been linked to cardiovascular disease. The study of Sharma et al. (1998) showed that the 'e' allele was over represented in hypertensive individuals, consistent with $* 4$ and $* 8$ containing this allele being associated with elevated cardiovascular risk factors (Rodriguez et al. 2004). Cardiovascular risk factors such as increased blood sugar, triglycerides, total lipids and systolic blood pressure occur significantly less frequently in PD compared with controls (Haugarvoll et al. 2005; Scigliano et al. 2006), consistent with the observed *6 protective effect for PD (present study). Rather than a significant $T H$ effect, Rodriguez et al. (2004) suggest that the long repeat insertion in the INS promoter contributes most to cardiovascular association with the IGF2-INS-TH haplotypes. In the present study we did not find any underlying association between the INS gene and PD.

Variability in the $T H$ gene has also been linked to smoking behaviour. Smoking behaviour is negatively associated with PD (De Reuck et al. 2005; Wirdefeldt et al. 2005). In non-PD Caucasian cohorts the HUMTH01 'b’ allele confers protection against tobacco dependence (Anney et al. 2004; Olsson et al. 2004). However we failed to see any over-representation of this allele in PD and were unable to find any differences in IGF2-INS-TH frequencies when smoking status and life-long cigarette smoking exposure in terms of pack-years were 
investigated as dependent variables in our cohort (data not shown). This may be due to our cohort being selected for PD, although we included smoking status as a covariant in our association studies.

The IGF2 gene or gene product has not been previously investigated in PD. The IGF2 gene is imprinted in prenatal development but both alleles are expressed in the adult human brain (Pham et al. 1998). Our results suggest that a polymorphism in this gene or a causative entity in tight linkage disequilibrium with the rs680 ' $\mathrm{A}$ ' allele is protective for PD. The rs680 'A' allele has been associated with higher plasma IGF2 protein levels and lower body weights (O'Dell et al. 1997; Gaunt et al. 2001; Sandhu et al. 2003). Interestingly, low body mass index, potentially reflecting a wider metabolic disturbance, is observed in PD (Bachmann and Trenkwalder 2006), although plasma IGF2 levels have not been assessed in PD patients to our knowledge. The IGF2 gene has also been linked to the neurodegeneration in Alzheimer's disease where reduced levels of insulin, IGF1, and IGF2 and their receptors transcripts are seen with advancing stages of the disease (Rivera et al. 2005).

As with all genetic association studies, there are many potential biases that can influence outcome and lead to false-positive findings, so replication of these findings in an independent sample is necessary for confirmation. The advantages of our study include the consistency of the genetic data from our tightly age and gender matched cases and controls, and the use of a validated questionnaire to assess non-genetic factors. In particular our genotyping data was comparable to other Caucasian cohorts for HUMTH01 (Anney et al. 2004; Olsson et al. 2004; Rodriguez et al. 2006; Sharma et al. 1998) and both SNPs (Rodriguez et al. 2006). Despite this, the rs689 SNP remained outside Hardy-Weinberg equilibrium in our control population even after replication. Admittedly our controls were a convenient sample of both electoral roll 
volunteers and spouses, but the potential overmatching of the latter for environmental factors seems unlikely to affect our results.

Overall our results suggest that there is at least one common variant in the IGF2-INS-TH gene cluster that affects or is associated with susceptibility to PD. It remains unclear which gene in the cluster harbours this variant(s) and whether the effect is brain-specific or part of a more systemic syndrome.

\section{ACKNOWLEDGEMENTS}

We wish to thank Madelaine Ranola and Coral Gartner for assistance with case ascertainment, Tonia Russell and Gerhard Siebert for assistance with DNA processing, and Heather McCann, Francine Griffiths and Nadeeka Dissanayaka for laboratory assistance. The Australian Brain Foundation provided core funding for this project (LL, KD) with other research funds from NHMRC project grants \#222727 (GH, DR) and \#401537 (GM, GH, PS, DR), and the Geriatric Medical Foundation of Queensland (GM). 


\section{REFERENCES}

Albanese V, Biguet NF, Kiefer H, Bayard E, Mallet J, Meloni R (2001) Quantitative effects on gene silencing by allelic variation at a tetranucleotide microsatellite. Hum Mol Genet 10:1785-1792

Anney RJ, Olsson CA, Lotfi-Miri M, Patton GC, Williamson R (2004) Nicotine dependence in a prospective population-based study of adolescents: the protective role of a functional tyrosine hydroxylase polymorphism. Pharmacogenetics 14:73-81

Bachmann CG, Trenkwalder C (2006) Body weight in patients with Parkinson's disease. Mov Disord 21:1824-1830

Chung CY, Seo H, Sonntag KC, Brooks A, Lin L, Isacson O (2005) Cell type-specific gene expression of midbrain dopaminergic neurons reveals molecules involved in their vulnerability and protection. Hum Mol Genet 14:1709-1725

De Reuck J, De Weweire M, Van Maele G, Santens P (2005) Comparison of age of onset and development of motor complications between smokers and non-smokers in Parkinson's disease. J Neurol Sci 231:35-39

Deng Y, Newman B, Dunne MP, Silburn PA, Mellick GD (2004) Case-only study of interactions between genetic polymorphisms of GSTM1, P1, T1 and Z1 and smoking in Parkinson's disease. Neurosci Lett 366:326-331

Doris PA (2002) Hypertension genetics, single nucleotide polymorphisms, and the common disease:common variant hypothesis. Hypertension 39:323-331

Gaunt TR, Cooper JA, Miller GJ, Day IN, O'Dell SD (2001) Positive associations between single nucleotide polymorphisms in the IGF2 gene region and body mass index in adult males. Hum Mol Genet 10:1491-1501

Gelb DJ, Oliver E, Gilman S (1999) Diagnostic criteria for Parkinson disease. Arch Neurol 56:33-39

Haugarvoll K, Aarsland D, Wentzel-Larsen T, Larsen JP (2005) The influence of cerebrovascular risk factors on incident dementia in patients with Parkinson's disease. Acta Neurol Scand 112:386-390

Kunugi H, Kawada Y, Hattori M, Ueki A, Otsuka M, Nanko S (1998) Association study of structural mutations of the tyrosine hydroxylase gene with schizophrenia and Parkinson's disease. Am J Med Genet 81:131-133

Le Couteur DG, Muller M, Yang MC, Mellick GD, McLean AJ (2002) Age-environment and gene-environment interactions in the pathogenesis of Parkinson's disease. Rev Environ Health 17:51-64

Litvan I, Halliday G, Hallett M, Goetz CG, Rocca W, Duyckaerts C, Ben-Shlomo Y, Dickson DW, Lang AE, Chesselet MF, Langston WJ, Di Monte DA, Gasser T, Hagg T, Hardy J, Jenner P, Melamed E, Myers RH, Parker D, Jr., Price DL (2007) The etiopathogenesis of Parkinson disease and suggestions for future research. Part I. J Neuropathol Exp Neurol 66:251-257

Mizuta I, Satake W, Nakabayashi Y, Ito C, Suzuki S, Momose Y, Nagai Y, Oka A, Inoko H, Fukae J, Saito Y, Sawabe M, Murayama S, Yamamoto M, Hattori N, Murata M, Toda $\mathrm{T}$ (2006) Multiple candidate gene analysis identifies alpha-synuclein as a susceptibility gene for sporadic Parkinson's disease. Hum Mol Genet 15:1151-1158

O'Dell SD, Miller GJ, Cooper JA, Hindmarsh PC, Pringle PJ, Ford H, Humphries SE, Day IN (1997) Apal polymorphism in insulin-like growth factor II (IGF2) gene and weight in middle-aged males. Int J Obes Relat Metab Disord 21:822-825

Olsson C, Anney R, Forrest S, Patton G, Coffey C, Cameron T, Hassett A, Williamson R (2004) Association between dependent smoking and a polymorphism in the tyrosine 
hydroxylase gene in a prospective population-based study of adolescent health. Behav Genet 34:85-91

Pham NV, Nguyen MT, Hu JF, Vu TH, Hoffman AR (1998) Dissociation of IGF2 and H19 imprinting in human brain. Brain Res 810:1-8

Plante-Bordeneuve V, Davis MB, Maraganore DM, Marsden CD, Harding AE (1994) Tyrosine hydroxylase polymorphism in familial and sporadic Parkinson's disease. Mov Disord 9:337-339

Quesada A, Micevych PE (2004) Estrogen interacts with the IGF-1 system to protect nigrostriatal dopamine and maintain motoric behavior after 6-hydroxdopamine lesions. J Neurosci Res 75:107-116

Rivera EJ, Goldin A, Fulmer N, Tavares R, Wands JR, de la Monte SM (2005) Insulin and insulin-like growth factor expression and function deteriorate with progression of Alzheimer's disease: link to brain reductions in acetylcholine. J Alzheimers Dis 8:247268

Rodriguez S, Gaunt TR, O'Dell SD, Chen XH, Gu D, Hawe E, Miller GJ, Humphries SE, Day IN (2004) Haplotypic analyses of the IGF2-INS-TH gene cluster in relation to cardiovascular risk traits. Hum Mol Genet 13:715-725

Rodriguez S, Huang S, Chen XH, Gaunt TR, Syddall HE, Gilg JA, Miller GJ, Cooper CC, Cook DG, Whincup PH, Day IN (2006) A study of TH01 and IGF2-INS-TH haplotypes in relation to smoking initiation in three independent surveys. Pharmacogenet Genomics 16:15-23

Sandhu MS, Gibson JM, Heald AH, Dunger DB, Wareham NJ (2003) Low circulating IGF-II concentrations predict weight gain and obesity in humans. Diabetes 52:1403-1408

Scigliano G, Musicco M, Soliveri P, Piccolo I, Ronchetti G, Girotti F (2006) Reduced risk factors for vascular disorders in Parkinson disease patients: a case-control study. Stroke 37:1184-1188

Sharma P, Hingorani A, Jia H, Ashby M, Hopper R, Clayton D, Brown MJ (1998) Positive association of tyrosine hydroxylase microsatellite marker to essential hypertension. Hypertension 32:676-682

Wei J, Ramchand CN, Hemmings GP (1997) Possible association of catecholamine turnover with the polymorphic (TCAT)n repeat in the first intron of the human tyrosine hydroxylase gene. Life Sci 61:1341-1347

Wirdefeldt K, Gatz M, Pawitan Y, Pedersen NL (2005) Risk and protective factors for Parkinson's disease: a study in Swedish twins. Ann Neurol 57:27-33

Zhang L, Rao F, Wessel J, Kennedy BP, Rana BK, Taupenot L, Lillie EO, Cockburn M, Schork NJ, Ziegler MG, O'Connor DT (2004) Functional allelic heterogeneity and pleiotropy of a repeat polymorphism in tyrosine hydroxylase: prediction of catecholamines and response to stress in twins. Physiol Genomics 19:277-291 


\section{Tables}

Table 1. Common IGF2-INS-TH haplotypes for cases and controls

\begin{tabular}{|c|c|c|c|}
\hline Label $^{\mathbf{a}}$ & rs680-rs689-TH & \%Freq. Ca (N) & \%Freq. Co (N) \\
\hline$* 1$ & G-A-a & $23.4(97.9)$ & $21.9(91.9)$ \\
\hline$* 5$ & A-A-d & $11.7(49.0)$ & $14.1(59.3)$ \\
\hline$* 2$ & G-A-b & $16.4(68.5)$ & $13.4(56.4)$ \\
\hline$* 3$ & G-A-e & $9.9(41.4)$ & $12.3(51.6)$ \\
\hline$* 4$ & G-T-e & $12.1(50.4)$ & $11.4(47.7)$ \\
\hline$* \mathbf{6}^{\text {bd }}$ & A-T-e & $\mathbf{5 . 1 ( 2 1 . 1 )}$ & $\mathbf{1 1 . 0}(\mathbf{4 6 . 2})$ \\
\hline$* 7$ & G-A-c & $3.2(13.6)$ & $3.7(15.6)$ \\
\hline$* 8^{\text {cd }}$ & G-T-c & $6.3(26.4)$ & $2.9(12.0)$ \\
\hline Others $(* 9-20)$ & \multicolumn{2}{|l}{$11.9(50.2)$} & $9.3(38.8)$ \\
\hline PD-case control $\chi^{2}$ analysis $=20.4$, df $=8$, p-value $\leq 0.01$ & \\
\hline
\end{tabular}

${ }^{\text {a }}$ haplotype nomenclature from Rodriguez et al., 2004

${ }^{\mathrm{b}}$ unadjusted $\mathrm{OR}=0.42,95 \%$ C.I. $=0.25-0.72, \mathrm{p}=0.001$; Ref. $=$ all other haplotypes

${ }^{\mathrm{c}}$ unadjusted $\mathrm{OR}=2.31,95 \%$ C.I. $=1.17-4.56, \mathrm{p}=0.02$; Ref. $=$ all other haplotypes

${ }^{\mathrm{d}}$ significant $\mathrm{p}$-value $=0.006$ corrected for 9 comparisons 
Table 2. Genotype frequencies and analysis of individual polymorphisms

\begin{tabular}{|c|c|c|c|c|c|c|}
\hline polymorphism & & cases $(\%)$ & controls (\%) & $\mathbf{O R}^{\mathrm{a}}$ & 95\% C.I. & p-value \\
\hline \multirow[t]{3}{*}{ IGF2-rs680 } & no 'A' allele & $114(54)$ & $101(48)$ & 1.00 & & \\
\hline & 1 'A' allele & $86(41)$ & $85(40)$ & 0.89 & $0.59-1.34$ & 0.58 \\
\hline & 2 'A' alleles & $11(5)$ & $25(12)$ & 0.35 & 0.16-0.77 & 0.01 \\
\hline \multirow[t]{3}{*}{ INS-rs689 } & no 'T' allele & $117(55)$ & $103(49)$ & 1 & & \\
\hline & 1 'T' allele & $79(37)$ & 97 (46) & 0.71 & $(0.48-1.07)$ & 0.10 \\
\hline & 2 'T' alleles & $16(8)$ & $10(5)$ & 1.35 & $0.59-3.13$ & 0.48 \\
\hline \multirow[t]{3}{*}{ HUMTH01 } & no ‘e’ allele & $104(48)$ & 83 (39) & 1.00 & & \\
\hline & 1 'e' allele & $90(42)$ & $105(49)$ & 0.67 & $0.45-1.01$ & 0.06 \\
\hline & 2 'e' alleles & $21(10)$ & $27(13)$ & 0.59 & $0.31-1.14$ & 0.12 \\
\hline
\end{tabular}

${ }^{\mathrm{a}}$ adjusted for age, gender and smoking status by logistic regression modelling 
Table 3. Results of multivariate logistic regression analysis

\begin{tabular}{|l|c|c|c|}
\hline Risk factor & OR & 95\% C.I & p-value \\
\hline age & 1.00 & $0.98-1.03$ & 0.82 \\
\hline gender & 1.06 & $0.71-1.60$ & 0.76 \\
\hline smoking status & 0.78 & $0.52-1.17$ & 0.22 \\
\hline HUMTH01 'e' allele carriers & 0.68 & $0.47-1.03$ & 0.07 \\
\hline IGF2-rs680 'AA' genotype & $\mathbf{0 . 3 7}$ & $\mathbf{0 . 1 7 - 0 . 8 0}$ & $\mathbf{0 . 0 1}$ \\
\hline
\end{tabular}




\section{Figure Legend}

Figure 1. Schematic of the IGF2-INS-TH gene cluster at Chr:11p15.5.

Insulin-like growth factor (IGF) 2, insulin precursor (INS) and tyrosine hydroxylase (TH) genes are found together at the telomeric end of the short arm of chromosome 11 (11p15.5) along with the IGF2 anti-sense gene (IGF2AS) transcribed from the negative strand. Three polymorphisms tag the majority of common genetic variation in this region: IGF2-rs680 (SNP in 3'UTR of IGF2), INS-rs689 (SNP in intron 1of INS) and HUMTH01 (tetranucleotide repeat in intron1 of $T H$ ). 
Figure 1

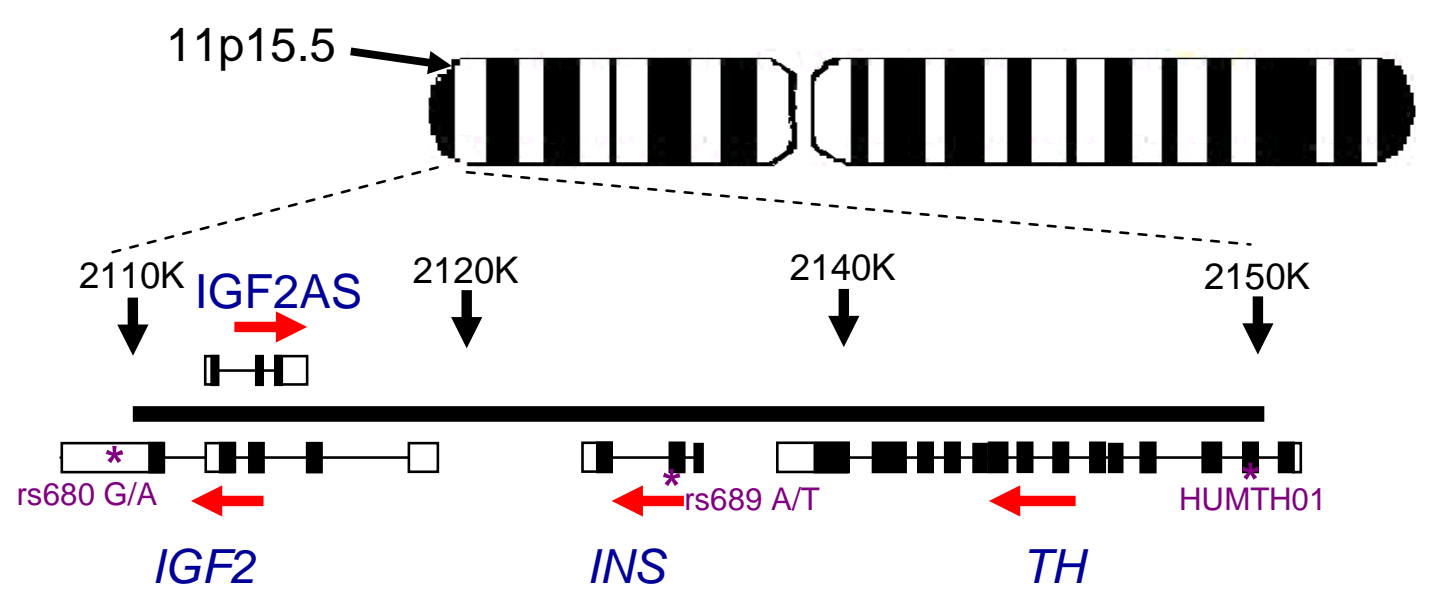


Table S1: Allele and genotype frequencies and analyse

\begin{tabular}{|c|c|c|c|c|c|c|c|}
\hline \multicolumn{5}{|l|}{ Genotypes } & \multicolumn{3}{|c|}{ 95\% confidence intervals } \\
\hline & Genotype & cases (\%) & controls (\%) & $\mathrm{OR}^{\mathrm{a}}$ & lower & upper & p-value $^{\mathrm{b}}$ \\
\hline \multirow[t]{3}{*}{ IGF2-rs680 } & GG & $114(54)$ & $101(48)$ & 1 & & & \\
\hline & AG & $86(41)$ & $85(40)$ & 0.89 & 0.59 & 1.34 & 0.58 \\
\hline & $\mathbf{A A}$ & $11(5)$ & $25(12)$ & 0.35 & 0.16 & 0.77 & 0.01 \\
\hline \multirow[t]{4}{*}{ INS-rs689 } & $\mathrm{AA}$ & $117(55)$ & $103(49)$ & 1 & & & \\
\hline & AT & $79(37)$ & $97(46)$ & 0.71 & 0.48 & 1.07 & 0.10 \\
\hline & $\mathrm{TT}$ & $16(8)$ & $10(5)$ & 1.35 & 0.59 & 3.13 & 0.48 \\
\hline & Genotype & cases $(\%)$ & controls (\%) & $\mathrm{OR}^{\mathrm{a}}$ & lower & upper & p-value ${ }^{\mathrm{c}}$ \\
\hline \multirow[t]{5}{*}{ HUMTH01 } & others & & & 1 & & & \\
\hline & e carriers & $111(52)$ & $132(61)$ & 0.66 & 0.45 & 0.97 & 0.04 \\
\hline & ee & $21(10)$ & $27(13)$ & 0.59 & 0.31 & 1.14 & 0.12 \\
\hline & c carriers & $42(20)$ & $34(16)$ & 1.32 & 0.8 & 2.18 & 0.28 \\
\hline & $\mathrm{CC}$ & $3(1)$ & $1(0.5)$ & n.d & & & \\
\hline \multicolumn{5}{|l|}{ Alleles } & \multicolumn{3}{|c|}{ 95\% confidence intervals } \\
\hline & Allele & cases $(\%)$ & controls (\%) & $\mathrm{OR}^{\mathrm{d}}$ & upper & lower & p-value \\
\hline \multirow[t]{2}{*}{ IGF2-rs680 } & G & $314(74)$ & $287(68)$ & & & & \\
\hline & A & $108(24)$ & $135(32)$ & 0.73 & 0.54 & 0.99 & 0.04 \\
\hline \multirow[t]{3}{*}{ INS-rs689 } & A & $313(74)$ & $303(72)$ & & & & \\
\hline & $\mathrm{T}$ & $111(26)$ & $117(28)$ & 0.92 & 0.68 & 1.24 & 0.58 \\
\hline & Allele & cases $(\%)$ & controls (\%) & $\mathrm{OR}^{\mathrm{e}}$ & upper & lower & p-value $^{f}$ \\
\hline \multirow[t]{5}{*}{ HUMTH01 } & $\mathrm{a}$ & $114(27)$ & $104(24)$ & 1.16 & 0.76 & 1.77 & \\
\hline & $\mathrm{b}$ & $79(18)$ & $63(15)$ & 1.24 & 0.74 & 2.06 & 0.54 \\
\hline & $\mathrm{C}$ & $48(11)$ & $36(8)$ & 0.78 & 0.50 & 1.22 & 0.45 \\
\hline & $\mathrm{d}$ & $57(13)$ & $68(13)$ & 0.76 & 0.53 & 1.08 & 0.23 \\
\hline & e & $132(31)$ & $159(31)$ & 1.16 & 0.76 & 1.77 & 0.12 \\
\hline \multicolumn{8}{|c|}{$\mathrm{c} 2=7.45, \mathrm{df}=4, \mathrm{p} \leq 0.11$} \\
\hline
\end{tabular}

adds ratios adjusted for age, gender and smoking status by logistic regression modelling

${ }^{\mathrm{b}}$ significance level at $\mathrm{p}=0.025$

${ }^{\mathrm{c}}$ significance level at $\mathrm{p}=0.005$ following correction for eight comparisons

${ }^{\mathrm{d}}$ unadjusted odds ratios

e unadjusted odds ratios; ref = other alleles

${ }^{\mathrm{f}}$ significance level at $\mathrm{p}=0.01$ 